\title{
Erratum to: Self-citation in American Physiological Society Journals
}

\author{
Alexander N. Larcombe $\cdot$ Sasha C. Voss
}

Published online: 21 January 2011

(c) Akadémiai Kiadó, Budapest, Hungary 2011

\section{Erratum to: Scientometrics DOI 10.1007/s11192-010-0328-z}

Because of an unfortunate mistake of the typesetter the paper 11192-010-0328-z displays the wrong title.

"Self-citation: comparison between Radiology, European Radiology and Radiology for 1997-1998"

Should be replaced with:

"Self-citation in American Physiological Society Journals"

The online version of the original article can be found under doi:10.1007/s11192-010-0328-z.

A. N. Larcombe $(\bowtie)$

Division of Clinical Sciences, Telethon Institute for Child Health Research, Centre for Child Health Research, University of Western Australia, P.O. Box 855, West Perth, WA 6872, Australia e-mail: alexanderl@ichr.uwa.edu.au

S. C. Voss

Centre for Forensic Science M420, The University of Western Australia, 35 Stirling Highway, Crawley, WA 6009, Australia 